\title{
Streptomyces violaceoruber ES: A Producer of Bioprospective Metabolite for Rapid and Green Synthesis of Antibacterial Silver Nanoparticles
}

\author{
Mohamed I. Abou-Dobara, A. K.A. El-Sayed ${ }^{\#}$ and Noha F. Omar \\ Botany and Microbiology Department, Faculty of Science, Damietta University, \\ Damietta P. O. Box 34517, Egypt.
}

\begin{abstract}
$\mathbf{A}$ N ISOLATE of Streptomyces was phenotypically, morphologically and physiologically characterized and identified as Streptomyces violaceoruber ES. Its identification was confirmed using 16S rRNA gene sequencing. It produced a metabolite containing deep pink pigment that might be involved in silver nanoparticles (AgNPs) biosynthesis. Both crude metabolite on starch nitrate medium and partially purified metabolite with ammonium sulphate precipitation were tested for AgNPs synthesis. The biosynthesis protocol had environmental advantages of green synthesis and superior nanoparticles properties included regular rounded shape, size range from $13 \mathrm{~nm}$ to $27 \mathrm{~nm}$, and bactericidal efficiency. The AgNPs synthesis was performed within one minute at room temperature and sun light. This guarantees high biosafety, low cost, less consumption of energy, rapid and simplicity of its biosynthesis. Furthermore, the synthesized AgNPs showed antibacterial activity against multidrug resistant strains of $E$. coli, $K$. pneumoniae and $P$. aeruginosa. Also, it had synergistic effect with gentamycin against $P$. aeruginosa.
\end{abstract}

Keywords: Streptomyces, 16S rDNA sequencing, Silver nanoparticles, Antibacterial, Green synthesis.

\section{Introduction}

Metallic nanoparticles have various applications in the field of biotechnology. Among various metal nanoparticles, silver nanoparticles (AgNPs) represent an important nanomedicine-based advance including antimicrobials, therapeutics, and biomolecular detection. In addition, it is used in biolabeling sensors and catalysis. A number of chemical and physical methods have been developed for the synthesis of AgNPs including for example aqueous-solution chemical reduction, nonaqueous chemical reduction, template method, electrochemical reduction, photocatalytic reduction, microwave assisted synthesis, irradiation reduction. Generally, the physical methods have low yields, while the chemical methods cause contamination due to the chemical precursors, use of toxic solvents and the generation of hazardous by-products (Wang et al., 2007).

Biosynthesis methods have emerged as a simple, clean and viable alternative to chemical and physical methods. Several biosynthesis methods using fungi and enterobacteria (Mokhtari et al., 2009 and Balakumaran et al., 2016) have been suggested. These methods share the common methodology whereby silver nitrate solution is added to a microbial supernatant. Reducing agents in the microbial supernatant reduce $\mathrm{Ag}^{+}$to $\mathrm{AgNPs}$ under constant conditions. However, some of these microbes are pathogens that might contaminate AgNPs used in medical applications. These processes were rather slow (Saifuddin et al., 2009) which limits the industrial process of biosynthesis. Therefore, there is a need to develop a rapid and ecofriendly process for the synthesis of AgNPs.

Streptomyces is a very important safe microorganism for the production of several antibiotics and enzymes of commercial value. However, a few studies in the last five years have examined AgNPs biosynthesis methods using Streptomyces species. The first study was performed by Sadhasivam et al. (2010) who used $S$. hygroscopicus. This was followed by some

\#Corresponding author email: akaelsayed@yahoo.co.uk

DOI :10.21608/ejbo.2017.1017.1089

(C)2017 National Information and Documentation Center (NIDOC) 
studies using many different Streptomyces species (Tsibakhashvili et al., 2011; Zonooz \& Salouti, 2011; Alani et al., 2012; Selvakumar et al., 2012; Shetty et al., 2012; Sivalingam et al., 2012; ElNaggar \& Abdelwahed, 2014; Sanjenbam et al., 2014; Subashini et al., 2014; Kumar et al., 2015; Manivasagan et al., 2015 and Shanmugaiah et al., 2015). They had the drawback of slow biosynthesis. The only studies develop rapid and safe biosynthesis process, to our knowledge; used S. coelicolor Klmp33 (Manikprabhu \& Lingappa, 2013 a and b) and $S$. aegyptia (El-Naggar et al., 2014). However, these cases didn't have well control on the shape and size range of the synthesized AgNPs.

The present study aimed to get a good yield, well controlled, rapid green synthesis route of AgNPs employing the metabolite containing pigment produced by a new Streptomyces isolate. The general characters of this pigment were also investigated. Keeping the knowledge of AgNPs antibacterial activity in mind, the antibacterial activity and synergetic effects with antibiotics of synthesized AgNPs were in our focus.

\section{Materials And Methods}

\section{Microorganisms}

Streptomyces strain used in this investigation was isolated on starch nitrate agar medium from a soil sample collected from Sharm El-Sheikh, Sinai, Egypt. Bacillus cereus strain was obtained from the culture collection of Microbiology Laboratory, Botany and Microbiology Department, Faculty of Science, Damietta University, Egypt. Bacterial strains (Escherichia coli, Klebsiella pneumoniae and Pseudomonas aeruginosa) were a gift from Dr. Hazem Saleh, Urology and Nephrology Center, Mansoura University, Egypt. They were isolated from clinical samples and identified by automated microscan (DADE BEHRING, USA). Table 1 shows their susceptibility to different antibiotics.

Classical characterization and identification of Streptomyces isolate

The identification of Streptomyces isolate was carried out according to I.S.P. articles (Nonomura, 1974) and Bergey's Manual of Systematic Bacteriology ( $1^{\text {st }}$ edition) (Williams et al., 1989).

The scanning electron microscopy (SEM, JEOL, JSM-5300, USA) at $25 \mathrm{KeV}$ was used for micromorphological properties investigation.
TABLE 1. Bacterial strains susceptibility to different antibiotic.

\begin{tabular}{|l|c|c|c|}
\hline Antibiotics & $\begin{array}{c}\boldsymbol{E} \text {. } \\
\text { coli }\end{array}$ & $\begin{array}{c}\boldsymbol{K} \text {. } \\
\text { pneumoniae }\end{array}$ & $\begin{array}{c}\boldsymbol{P} \text {. } \\
\text { aeruginos } \boldsymbol{~}\end{array}$ \\
\hline Ampicillin & $\mathrm{S}$ & $\mathrm{R}$ & $\mathrm{R}$ \\
\hline $\begin{array}{l}\text { Amoxicillin/ } \\
\text { clavulanic acid }\end{array}$ & $\mathrm{S}$ & $\mathrm{R}$ & $\mathrm{R}$ \\
\hline Ticarcillin & $\mathrm{S}$ & $\mathrm{R}$ & $\mathrm{R}$ \\
\hline $\begin{array}{l}\text { Piperacillin/ } \\
\text { tazobactam }\end{array}$ & $\mathrm{S}$ & $\mathrm{R}$ & $\mathrm{S}$ \\
\hline Cefalotin & $\mathrm{S}$ & $\mathrm{R}$ & $\mathrm{R}$ \\
\hline Cefoxitin & $\mathrm{S}$ & $\mathrm{S}$ & $\mathrm{R}$ \\
\hline Cefotaxime & $\mathrm{S}$ & $\mathrm{R}$ & $\mathrm{R}$ \\
\hline Ceftazidime & $\mathrm{S}$ & $\mathrm{R}$ & $\mathrm{S}$ \\
\hline Imipenem & $\mathrm{S}$ & $\mathrm{S}$ & $\mathrm{S}$ \\
\hline Amikacin & $\mathrm{S}$ & $\mathrm{S}$ & $\mathrm{S}$ \\
\hline Gentamicin & $\mathrm{S}$ & $\mathrm{S}$ & $\mathrm{R}$ \\
\hline Netilmicin & $\mathrm{S}$ & $\mathrm{S}$ & $\mathrm{I}$ \\
\hline Tobramycin & $\mathrm{S}$ & $\mathrm{R}$ & $\mathrm{R}$ \\
\hline Nalidixic acid & $\mathrm{S}$ & $\mathrm{R}$ & $\mathrm{R}$ \\
\hline Ciprofloxacin & $\mathrm{S}$ & $\mathrm{R}$ & $\mathrm{R}$ \\
\hline Norfloxacin & $\mathrm{S}$ & $\mathrm{R}$ & $\mathrm{R}$ \\
\hline Ofloxacin & $\mathrm{S}$ & $\mathrm{R}$ & $\mathrm{R}$ \\
\hline Nitrofurantoin & $\mathrm{S}$ & $\mathrm{R}$ & $\mathrm{R}$ \\
\hline $\begin{array}{l}\text { Trimethoprim/ } \\
\text { sulfamethoxazole }\end{array}$ & $\mathrm{R}$ & $\mathrm{R}$ & $\mathrm{R}$ \\
\hline S: sensitive, R: & & \\
\hline
\end{tabular}

S: sensitive, R: resistance and I: intermediate.

The occurrence of LL- or DL- hydroxyldiaminopimelic acid (hydroxyl-DAP) and whole cell sugars were determined by thin layer chromatography of whole cell hydrolysates according to Schon \& Groth (2006).

Molecular identification of Streptomyces isolate

The genomic DNA of the isolate was extracted as described by Kumar et al. (2010). The 16S rRNA gene was amplified by using the specific primer pair for Streptomyces species, Strep B: 5'ACAAGCCCTGGAAACGGGGT3' and StrepF: 5'ACGTGTGCAGCCCAAGACA3' (Rintala et al., 2001). The PCR product was sequenced by an automated sequencer (Macrogen, Korea) using the same previous primers.

\section{Alignment and phylogenetic analyses}

BLAST (Altschul et al., 1990 and Altschul et al., 1997) was performed for the resulting $16 \mathrm{~S}$ rDNA sequence to match the best similarities with other related sequences on database. The best DNA sequence similarities with our 16S rDNA region were obtained from NCBI GenBank and aligned using CLUSTAL Omega. Unalignable regions were excluded manually and the sequences from 
the same species and unidentified organisms were discarded. Finally, phylogenetic tree analysis was viewed and analyzed using MEGA version 4. The neighbor-joining was performed using the maximum composite likelihood methods (Tamura \& Nei, 1993). The values 20 or above were only considered and represented next to the phylogenetic tree branches with confidence levels estimated by 1000 bootstrap replicates.

\section{Production and characterization of Streptomyces pigment}

Streptomyces isolate was cultured in starch nitrate medium for 3 days at $30^{\circ} \mathrm{C}$ and 150 rpm. The extracellular produced red pigment was precipitated by $40 \%$ ammonium sulphate then separated by centrifugation at 5,000 rpm for $10 \mathrm{~min}$. The absorption spectrum of the red pigment was recorded using UV-Visible spectrophotometer from $200-900 \mathrm{~nm}$. The $\mathrm{pH}$ sensitivity of the pigment was tested by using $1 \mathrm{~N}$ $\mathrm{NaOH}$ and $1 \mathrm{~N} \mathrm{HCl}$. The sensitivity of the pigment to light was tested by exposing the pigment (acidified, alkalized and neutralized forms) to sun light. Also, the antibacterial activity of the pigment against $E$. coli and $B$. cereus was assayed.

\section{Synthesis of silver nanoparticles}

$10 \mathrm{ml}$ of $1 \mathrm{mM}$ silver nitrate was treated with $0.5 \mathrm{ml}$ of either crude metabolite containing pigment, partially separated pigment or pigment free crude metabolite. This was followed by exposure to direct sun light irradiation for different time periods (1, 5, 10, 15, $20 \mathrm{~min})$. A sample left in dark served as control.

The weight of resulting AgNPs was estimated after precipitation by centrifugation of the previously prepared reactions at $10,000 \mathrm{rpm}$ for $30 \mathrm{~min}$ and drying at room temperature.

\section{Characterization of silver nanoparticles \\ $U V$-visible spectral analysis}

The biosynthesized silver nanoparticles were monitored by change in color. AgNPs was preliminary characterized by the sample absorption spectra from 300 to $650 \mathrm{~nm}$ using UVVisible spectrophotometer (Unico 7200 SERIES). A sample left in dark was used as a control throughout the experiment.

Transmission Electron Microscope (TEM) analysis

To determine size and shape of silver nanoparticles, biosynthesized silver nanoparticles from the maximum time-point of production was examined by transmission electron microscope (JEOL, JEM-100CX, USA). Samples for this analysis were prepared by coating carbon-coated copper grids with aqueous silver nanoparticles. After 5 min., the extra solution was removed using blotting paper, and then the films on the grids were examined.

Antibacterial activity and synergistic effect of AgNPs with gentamicin

Antibacterial activity and synergistic effect of silver nanoparticles with gentamicin were determined by the disk diffusion method on Mueller-Hinton agar plates according to the guidelines by the Clinical and Laboratory Standards Institute (Clinical and Laboratory Standards, 2006). The surface of Mueller-Hinton agar plates was inoculated by streaking swab, dipped into bacterial suspension. Disks of sterilized filter papers were loaded with $20 \mu$ l containing $125 \mu \mathrm{g}$ of biosynthesized silver nanoparticle solution and put over the surface of the inoculated Mueller-Hinton agar plates. Also, discs of $30 \mu \mathrm{g}$ gentamicin were loaded with $20 \mu \mathrm{l}(125 \mu \mathrm{g})$ of biosynthesized silver nanoparticle solution and tested in comparing to gentamicin alone.

\section{Statistical analysis}

Data were statistically analyzed for variance using one-way analysis of variance (ANOVA) and two-way analysis of variance (ANOVA) by software system SPSS version 18.

\section{$\underline{\text { Results }}$}

\section{Convential characteristics and identification}

Cultural properties of the Streptomyces isolate were studied on 12 media. It was able to grow on different tested media with different growth intensity (Table 2). Generally, it belongs to grey series of Streptomycetes, forms pink substrate mycelium and produces soluble red pigment. The ability to produce pigment differs according to the cultural medium (Table 2). The SEM examination for its spore chain (Fig. 1) showed smooth spore arranged in spiral chain. Physiological and biochemical characteristics of the isolate were listed in Table 3. It could utilize a wide range of carbon sources and produce different enzymes including amylase, gelatinase, caseinase and nitrate reductase. However, it couldn't produce melanin pigment. Also, it was resistant 
to ampicillin and penicillin-G. The chemical analysis of the cell wall revealed cell wall type
I that is characteristic by non-characteristic sugar and L-DAP.

TABLE 2. Cultural characteristics of Streptomyces isolate.

\begin{tabular}{lcccc}
\hline Medium & Growth & Substrate mycelium & Aerial mycelium & Soluble pigment \\
\hline Starch casein agar & & Color of & light pinkish gray \\
Starch-nitrate agar & + & light red-pink & light gray & red \\
Inorganic salts-starch agar & ++++ & deep pink & pale whitish gray \\
Yeast extract-malt extract agar & ++ & light orange-yellow & pale gray & none \\
Oat meal agar & + & dark pink & light gray & none \\
Glycerol-asparagine agar & +++ & red & pray & none \\
Sucrose-nitrate agar & ++ & rose red & pale pinkish gray \\
Glycerol-nitrate agar & +++ & dark red-orange & pale pinkish gray \\
Glucose-nitrate agar & + & pale dull red & pale pinkish gray \\
Czapek-dox agar & ++ & pale weak red & pale magenta- gray & violet \\
Glycerol tyrosine agar & +++ & red & light gray & violet \\
Nutrient agar & ++ & pale or dark pink & pink & violet \\
\hline
\end{tabular}

+ light growth, ++ moderate growth, +++ good growth, ++++ very good growth

TABLE 3. Physiological and biochemical characteristics of Streptomyces isolate.

\begin{tabular}{|c|c|c|c|}
\hline Test & Result & Test & Result \\
\hline Enzymes: & & Melanin formation on: & \\
\hline Amylase & + & Peptone-yeast iron agar & - \\
\hline Gelatinase & + & Tyrosine agar & - \\
\hline Lecithinase & - & Carbon sources utilization: & \\
\hline Cellulase & - & L-arabinose & + \\
\hline Nitrate reductase & + & D-fructose & + \\
\hline Urease & + & D-glucose & + \\
\hline $\mathrm{H}_{2} \mathrm{~S}$ production & - & Maltose & - \\
\hline Caseinase & + & Sorbitol & - \\
\hline Sensitivity to antibiotics: & & D-lactose & + \\
\hline Ampicillin $(100 \mu \mathrm{g})$ & - & D-mannitol & + \\
\hline Penicillin-G $(100 \mu \mathrm{g})$ & - & Starch & + \\
\hline Garamycin $(100 \mu \mathrm{g})$ & + & Sucrose & + \\
\hline Streptomycin $(100 \mu \mathrm{g})$ & + & D-xylose & + \\
\hline Growth temperature: & & Meso-inositol & + \\
\hline $45^{\circ} \mathrm{C}$ & - & L-rhamnose & - \\
\hline $37^{\circ} \mathrm{C}$ & + & Sodium acetate & - \\
\hline $10^{\circ} \mathrm{C}$ & - & Raffinose & - \\
\hline Growth at pH 4.3 & + & Sodium citrate & + \\
\hline Cell wall chemical & & Cellulose & - \\
\hline structure: & glucose, mannose, ribose & Cellobiose & + \\
\hline Sugar pattern & (not characteristic sugar) & D-galactose & + \\
\hline \multirow{3}{*}{$\begin{array}{l}\text { Type of Diaminopimelic acid } \\
\text { (DAP) }\end{array}$} & \multirow{3}{*}{ L-DAP } & D-mannose & - \\
\hline & & Sodium pyruvate & + \\
\hline & & Glycerol & + \\
\hline
\end{tabular}

(+): positive result and (-): negative result. 


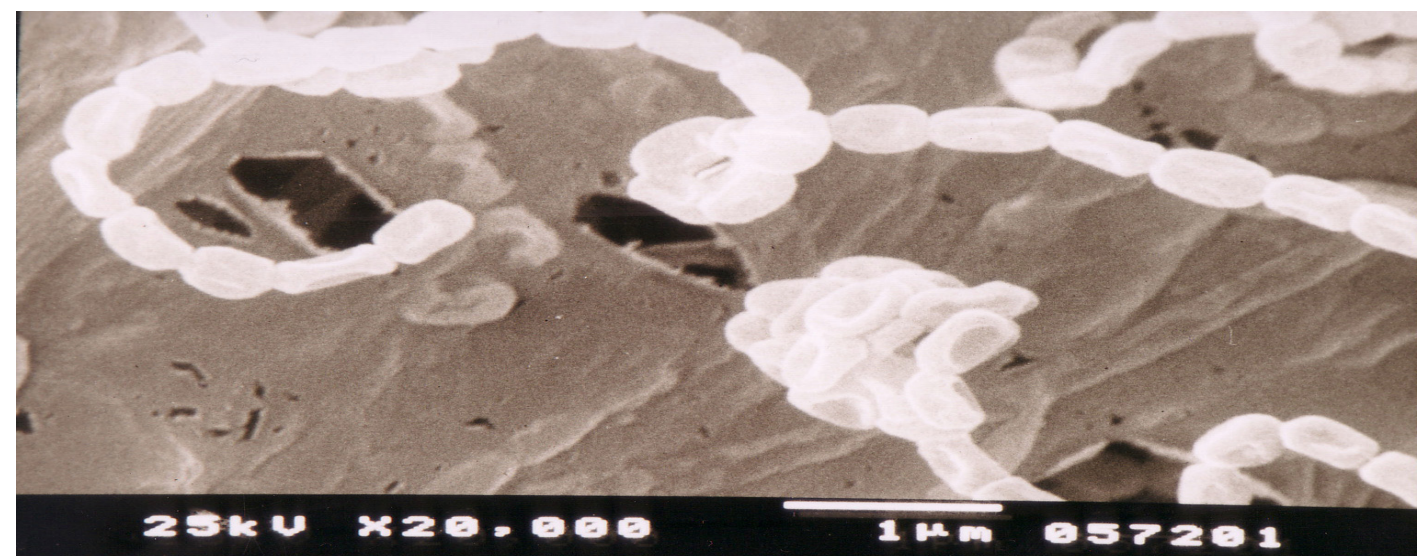

Fig. 1. Scanning electron micrograph of spore chain morphology of Streptomyces isolate.

Molecular identification

The obtained 16S rDNA partial sequence (1028 bp) was submitted to the GenBank with accession number (LK054490). The DNA sequence alignment of the $16 \mathrm{~S}$ rDNA partial sequence for the studied Streptomyces isolate showed the highest identity $(100 \%)$ with S. lienomycini (KF991646), S. thinghirensis (NR116901) and S. sp SF1 (KF793801). Some other different Streptomyces strains showed less similarity reached $99 \%$. The phylogenetic tree based on 16S rDNA sequence (Fig. 2) clustered the studied Streptomyces isolate in a clade that possessing approximate dissimilarity distance reached 0.004 with the neighbor clade containing S. violaceoruber ICSSB 1016 type strain. By comparing $16 \mathrm{~S}$ rRNA gene sequence and different studied characters with the reference species, we can conclude that this is a new isolate of Streptomyces violaceoruber.

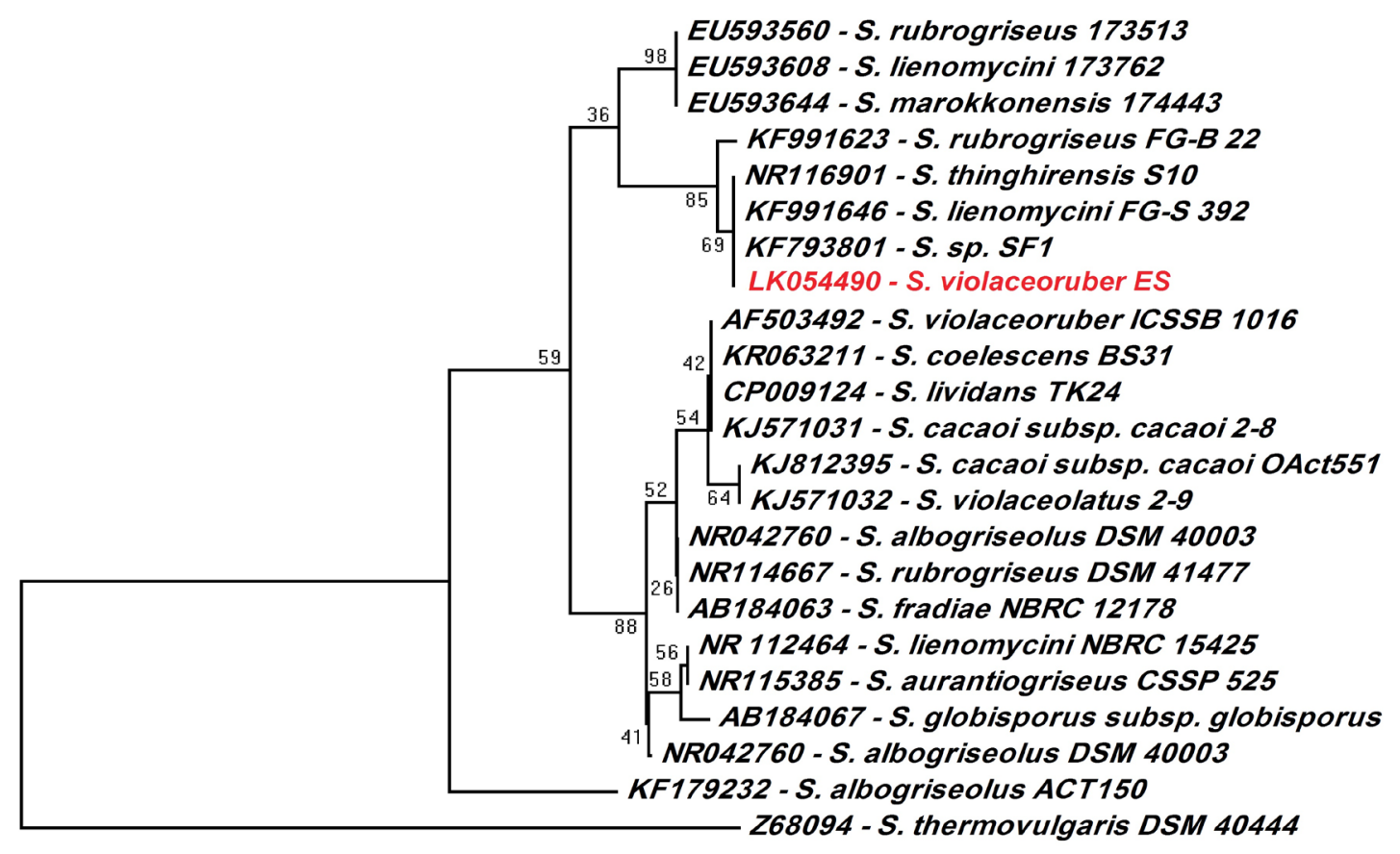

$\stackrel{5}{0.001}$

Fig. 2. Phylogenetic tree based on 16S rDNA sequence alignment for $S$. violaceoruber ES (Accession. no. LK054490) with other related species possessed the highest identity at database. The bootstrap values 20 or above were only considered and represented next to the phylogenetic tree branches with confidence levels estimated by 1000 bootstrap replicates. The scale represents the dissimilarity distance. 
Characteristics of the pigment

The Streptomyces isolate was found to produce a red pigment associated with its growth. The deep pink pigment (Fig. 3, I) was well produced after 3 days incubation on starch nitrate medium. This pigment was precipitated completely by adding $40 \%$ ammonium sulphate. The absorption of visible spectrum of the pigment at about $400 \mathrm{~nm}$ was shown in Fig. 3. This pigment has antibacterial activity against $B$. cereus. Also, it was sensitive to $\mathrm{pH}$ as it turns blue in alkaline medium and reddish in acidic medium (Fig. 3, II \& III). The sensitivity of the pigment to light depends on $\mathrm{pH}$. Acidic and neutralized forms were stable in light for days, while alkaline form turns into colorless after few hours in sun light.

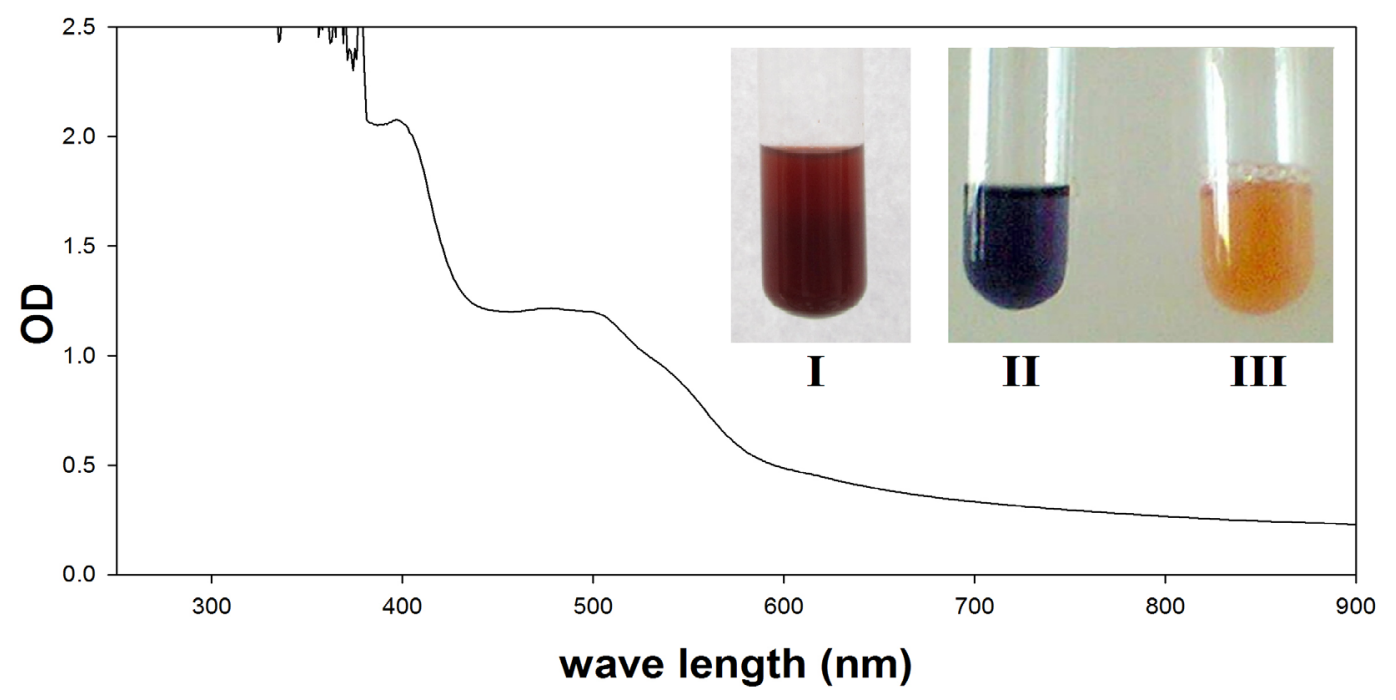

Fig. 3. UV-visible spectrum of $S$. violaceoruber ES pigment from $200-900 \mathrm{~nm}$. Separated deep pink pigment (I), Pigment treated with $1 \mathrm{~N} \mathrm{NaOH}$ (II) and $1 \mathrm{~N} \mathrm{HCl}$ (III).

The pigment produced by Streptomyces isolate, either as crude metabolites or partially purified metabolite, was used for silver nanoparticles biosynthesis in sun light. It was worth noting that this process didn't begin at any time in dark nor in absence of pigment. The biosynthesized AgNPs were monitored by change in color (Fig. 4 ). Results revealed that distinct surface plasmon peaks of AgNPs were observed after one minute in both cases (Fig. 4). The crude metabolite containing pigment showed significant higher amount of AgNPs (at 0.05 significant level) than partially purified metabolite containing pigment. After 5 min., in both cases, the AgNPs reached its maximum value. By increasing the time, there was no any significant effect (at 0.05 significant level) on the AgNPs biosynthesis. The weight of the biosynthesized AgNPs by partially purified metabolite containing pigment was $6.25 \mathrm{mg} / \mathrm{ml}$.

Estimation of the synthesized AgNPs shape and size

According to TEM examination, the biosynthesized AgNPs were spherical and well disperse in both cases (Fig. 5a and Fig. 6a). When using crude metabolite in the biosynthesis, the AgNPs size was $13.3 \mathrm{~nm} \pm 1.2 \mathrm{~nm}$. However, it increased significantly (at 0.05 significant level) in the case of using partially purified metabolite containing pigment to $27 \mathrm{~nm} \pm 2 \mathrm{~nm}$. Figure $5 \mathrm{~b}$ and Fig. 6b showed AgNPs size frequency \% according to TEM in the two cases.

Antibacterial activity of the synthesized AgNPs

The AgNPs synthesized by Streptomyces isolate crude metabolite were tested against three pathogenic bacterial strains. It inhibits the growth of the tested bacteria (Table 4). The less inhibition effect $(0.2 \mathrm{~mm})$ was against the multidrug resistant $P$. aeruginosa. However, it showed significant synergistic effect when companied with gentamicin (Table 4). In general, biosynthesized AgNPs by Streptomyces isolate crude metabolite revealed synergistic effect to antibiotic against resistant bacteria in addition to its antibacterial activity. 


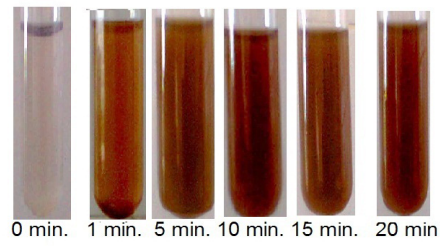

(A)

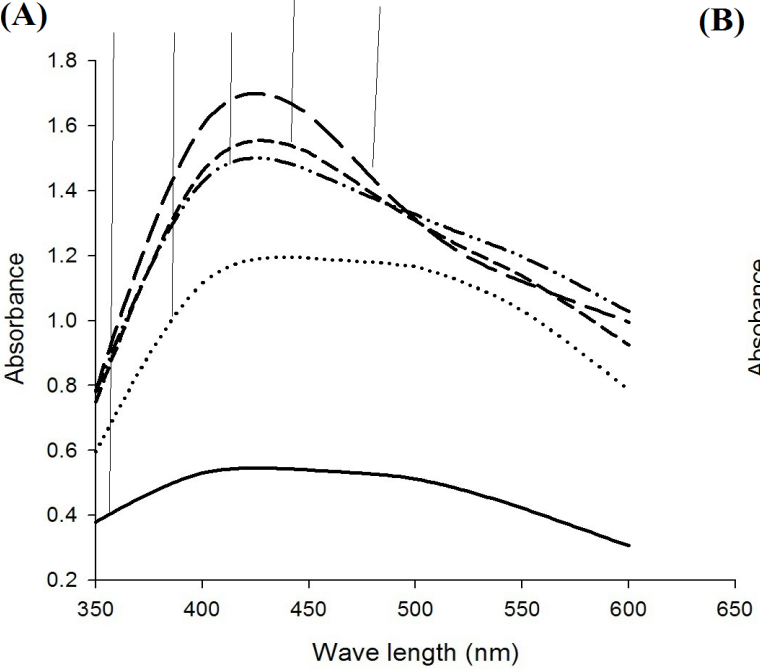

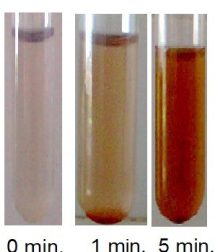

B)

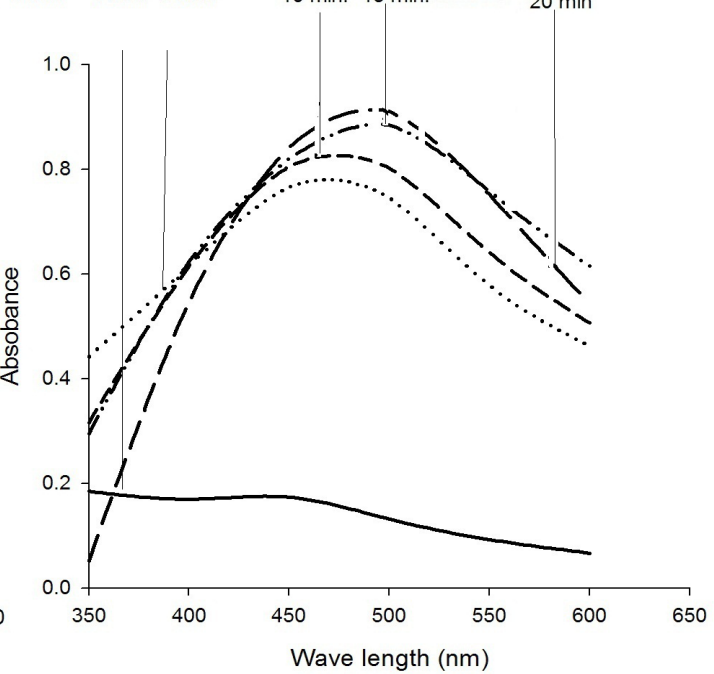

Fig. 4. UV-visible spectrum of biosynthesized silver nanoparticles by $S$. violaceoruber ES pigment in sun light at different time using (a) crude metabolite containing pigment and (b) partially purified metabolite containing pigment.

a

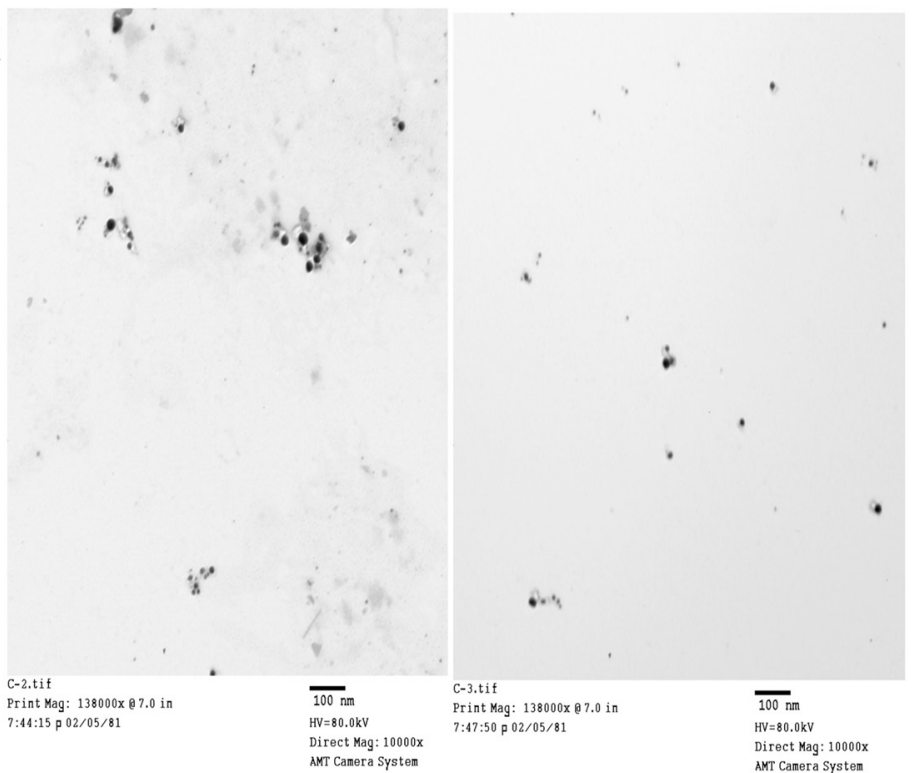

b

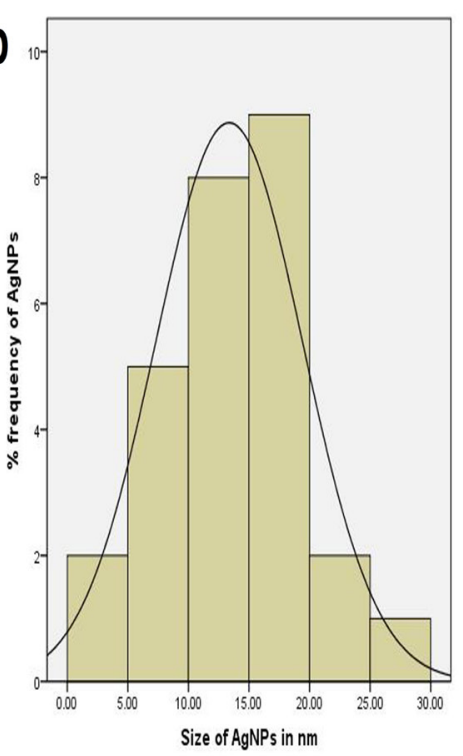

Fig. 5. Characterization of silver nanoparticles produced by $S$. violaceoruber ES crude metabolite containing pigment after exposure to sun light. (a) Transmission electron micrograph of produced AgNPs (scale bar corresponds to $100 \mathrm{~nm}$ ). (b) Histogram of AgNPs size frequency \% according to TEM. 

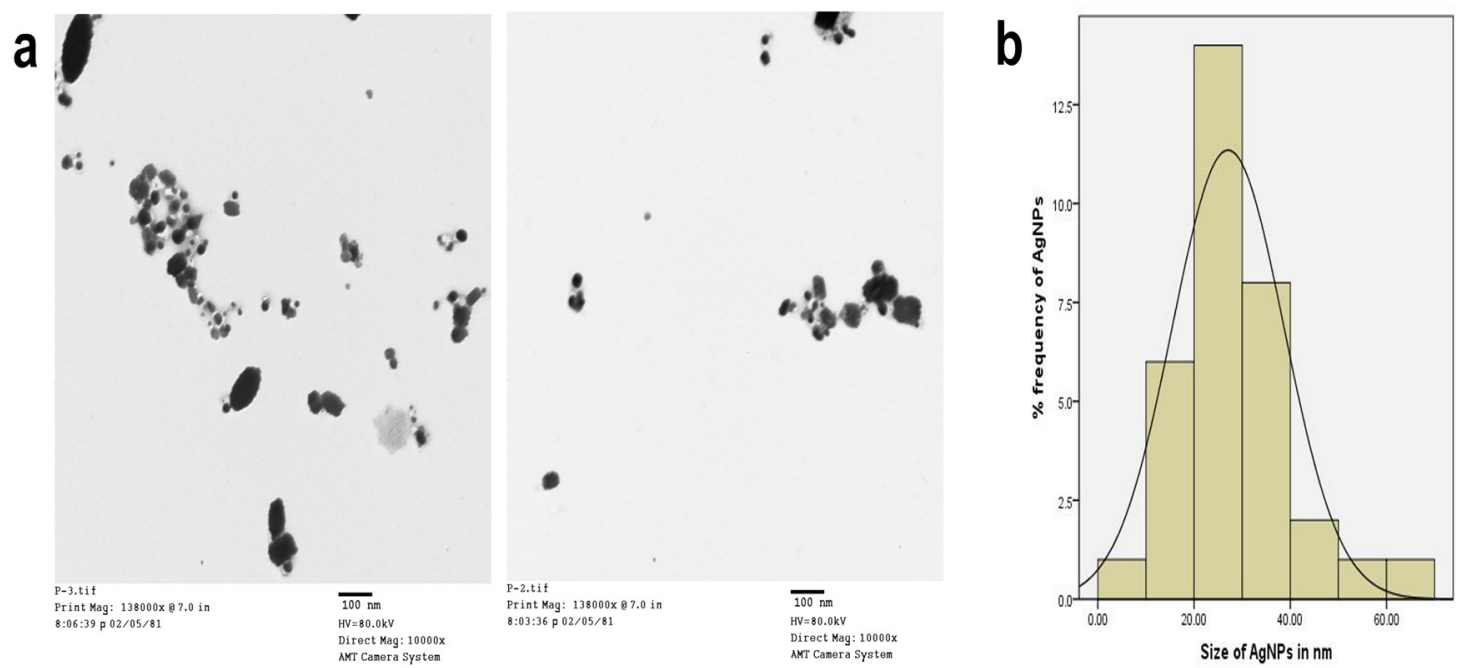

Fig. 6. Characterization of silver nanoparticles produced by $S$. violaceoruber ES partially purified metabolite containing pigment after exposure to sun light. (a) Transmission electron micrograph of produced AgNPs (scale bar corresponds to $100 \mathrm{~nm}$ ). (b) Histogram of AgNPs size frequency \% according to TEM.

TABLE 4. Antibacterial activity and synergistic effect of AgNPs synthesized by $S$. violaceoruber ES crude pigment against different bacteria. The results were recorded as the diameter of inhibition zone (mm).

\begin{tabular}{lcccc}
\hline Pathogenic bacteria & $\begin{array}{c}\text { AgNPs } \\
(\mathbf{2 0} \boldsymbol{\mu l})\end{array}$ & $\begin{array}{c}\text { Gentamicin } \\
\mathbf{( 3 0} \boldsymbol{\mu g})\end{array}$ & $\begin{array}{c}\text { AgNPs \& } \\
\text { Gentamicin }\end{array}$ & $\begin{array}{c}\text { \% fold increase in } \\
\text { Gentamicin effect }\end{array}$ \\
\hline E. coli & 2 & 20 & $24^{*}$ & 20 \\
K. pneumoniae & 2 & 22 & 24 & 9 \\
P. aeruginosa & 2 & - & $2.5^{*}$ & 250 \\
\hline
\end{tabular}

* indicates significant larger inhibition zone than that of gentamicin at 0.05 significant level.

\section{Disscussion}

The partial sequence of $16 \mathrm{~S}$ rRNA gene for Streptomyces strain showed great identity (99-100\%) with many different members of the genus Streptomyces. In accordance, the high similarity of $16 \mathrm{~S}$ rRNA gene sequences in Streptomycetaceae is found to weaken the statistical support for the backbone structure of the phylogenetic tree for this family (Labeda et al., 2012). Although, our Streptomyces strain showed $100 \%$ identity with $S$. lienomycini and $S$. thinghirensis, it is phenotypically different from those most closely related phylogenetic neighbors. The $S$. lienomycini and $S$. thinghirensis strains have different characters especially pigments production (Loqman et al., 2009). Furthermore, $S$. lienomycini has colorless substrate and produces no pigment. Also, it produces melanin pigment that is main differentiable character. On the other hand, $S$. thinghirensis possesses white grey aerial mycelium, yellow substrate and yellow pigment. Although, the phenotypic traits of the studied Streptomyces strain were more closely related to $S$. violaceoruber than the others, it exhibited less identity (99\%). This may be attributed to either the usage of $16 \mathrm{~S}$ rDNA partial sequence or the closely phylogenetic relations between these Streptomyces species. Labeda et al. (2012) illustrated the species diversity within Streptomycetaceae based on 16S rRNA gene sequences and divided it into 130 statistically supported clades. $S$. violaceoruber and $S$. lienomycini were clustered in the same clade 103, while $S$. thinghirensis was classified in the most related clade 102. Also, Labeda et al. (2012) reported that phylogenetic relations of taxa in the trees constructed from the 16S rDNA sequences confirmed that the phenotypic and morphological characteristics used for classification of species of Streptomyces are generally quite useful for species identification. So, the taxonomic value for the sequence of $16 \mathrm{~S}$ rDNA is primarily in the determination of novelty of unknown isolates of 
Streptomycetes, particularly since it shows at least some correlation with morphological and physiological characters. From the obtained phenotypic and genotypic data, it is clear that the studied Streptomyces strain represents a new isolate of $S$. violaceoruber ES which form grey aerial mycelium, pink substrate and red pigment.

In general, Streptomycetaceae is famous for pigment production and this character is used in its classification. S. violaceoruber is reported to produce the so-called indicator, redviolet to blue; pigment (Williams et al., 1989). This pigment is known as protoactinorhodin and belonged to the naphthoquinone chemical class (Korn-Wendisch \& Kutzner, 1981). By comparing the characters of $S$. violaceoruber ES pigment to those of $S$. violaceoruber (Williams et al., 1989), we predicate that it at least belongs to the same chemical class of naphthoquinone. Naphthoquinones are fully conjugated structures that interchange between quinone and hydroquinone. This could be a promising route to potential environmentally friendly approach to reduce silver and synthesis AgNPs.

The green synthesis of nanomaterials has many advantages as lowering production cost, avoiding environmental pollution, reducing physiological toxicity, and enhancing biological compatibility (Duan et al., 2015). The achievement of greener design for synthesis of nanoparticles depends on the selection of environmentally benign chemicals and on the methodological considerations. Cinelli et al. (2015) have developed an evaluation model to assess the synthesis protocols of nanopacticles. The selected criteria used in that model include type of reducing agent, type of capping agent, solvent typology, using of local resources, reaction time, reaction temperature, equipment type, and size range of ensuing nanoparticles. Based on these criteria, biosynthetic method developed in this study for producing AgNPs has distinct advantages over most other known methods. Since the metabolite of $S$. violaceoruber $\mathrm{ES}$, including pigment; represents the bioreductant medium. This is renewable, easy to be prepared at low cost and used in small amounts. Also, this protocol is performed within minutes at room temperature and sun light. This guarantees high biosafety, low cost, less consumption of energy, speed and simplicity of operation.
Turning the color into brown was used as an indicator to the biosynthesis of AgNPs. This color is a result of excitation of surface plasm on vibration in the AgNPs (Mulvaney, 1996). The position and shape of the plasmon absorption of AgNPs depends on particle size, stabilizing molecules, surface adsorbed particles and the dielectric constant of the medium (Krishnaraj et al., 2010). When crude metabolite used in the AgNPs biosynthesis process, it revealed higher absorbance levels than that of partially purified metabolite containing pigment, indicating that higher concentration of AgNPs was produced. This may be attributed to the presence of some components with excellent redox properties as sulfur-containing proteins and/or NADH dependent enzymes in the culture supernatant. These components may act as cofactors in the reduction of silver ions and the subsequent formation of AgNPs (Krishnaraj et al., 2010). In this study, we report the ability of $S$. violaceoruber $\mathrm{ES}$ to produce nitrate reductase that is one of the NADH dependent enzymes. However, it isn't the main factor in AgNPs formation as this reaction didn't occur in dark. It may act as a cofactor which increases the AgNPs formation when using crude metabolite. The role of nitrate reductase in the biosynthesis of silver nanoparticles was also previously reported (Alani et al., 2012). As a hypothetical mechanism, the pigment as water soluble quinone acts as an electron shuttle compound which activates in light and produce AgNPs. In accordance, Duan et al. (2015) reported that water-soluble quinones might function as an electron shuttle compound in the biosynthesis of AgNPs. While in crude metabolite the reductase and other proteins together with pigment may be responsible for the increased reduction of silver ions and subsequent increase formation of AgNPs. Regarding to the position of the plasmon absorption of AgNPs, the maximum absorbance remained close to $420 \mathrm{~nm}$ in the case of using crude metabolite indicates that the particles were well dispersed in the solution (Saifuddin et al., 2009). In contrast, partially purified metabolite containing pigment resulted in shifting AgNPs maximum absorbance toward 450 $\mathrm{nm}$ indicating some aggregations and increase in AgNPs size as confirmed by TEM analysis. This may be attributed to the elimination of some components that act as capping agents during the separation of pigment. The capping agents such as polysaccharides and some peptides are responsible to determine the morphologies and 
size of nanoparticles by protecting the surface from aggregation (Duan et al., 2015).

Many ecofriendly biosynthesis processes for the AgNPs synthesis have been developed. However, the main drawback of them is the longer time period required in comparison with conventional techniques. In most studies Streptomyces could synthesize AgNPs after one to seven days (Tsibakhashvili et al., 2011; Sivalingam et al., 2012; Sanjenbam et al., 2014; Shanmugaiah et al., 2015 and Kamel et al., 2016). On the other hand, S. violaceoruber ES provides a rapid green synthesis route within one to five minutes using photobiological method. It is predicated that photobiological methods will have tremendous upsurge in the field of nanobiotechnology. Few studies have found to use it. Solar irradiation was used with aqueous extract of Pleurotus florida oyster mushroom (Bhat et al., 2011) and with cell-free extracts of Bacillus amyloliquefaciens (Wei et al., 2012) to synthesize AgNPs. But $S$. violaceoruber $\mathrm{ES}$, in this study; and $S$. coelicolor Klmp 33 (Manikprabhu \& Lingappa, 2013a) still the only methods, to our knowledge; share the advantages of photobiological method with speed and renewable available reducing media. However, environmental advantages alone may not be sufficient to guarantee the green synthesis as a feasible solution for industrial realizations. Its applicability will only be reached if the nanoparticles are of superior properties (Duan et al., 2015). The main property should take in mind is the AgNPs size (Cinelli et al., 2015). It is believed that the efficacy of AgNPs depends on particle size as the smaller the diameter the bigger is surface then the better is the antibacterial efficacy. In this study, whether we use crude metabolite containing pigment or partially purified metabolite containing pigment the AgNPs still spherical in shape like most other microbialmediated synthesis. Also, its size lies in the best class $(0-30 \mathrm{~nm})$. In contrast, Manikprabhu \& Lingappa (2013a) reported irregular shape and size ranged in the third class $(30-60 \mathrm{~nm})$ using S. coelicolor Klmp 33 pigment. These characters may limit its applicability in spite of its green synthesis protocol advantages.

Regarding AgNPs antibacterial activity, AgNPs synthesized by the crude metabolite including pigment showed activity against $E$. coli, $K$. pneumoniae and $P$. aeruginosa. There are various theories on the action of AgNPs on microbes. It may interact with the peptidoglycan cell wall (Radzig et al., 2013). Smaller size of AgNPs can act on the cell membrane; further interact with DNA and bacterial proteins especially enzymes containing thiol groups leading to cell death (Fayaz et al., 2010 and Radzig et al., 2013). In addition, the influence of AgNPs on the bacterial biofilm formation was reported (Radzig et al., 2013). AgNPs biosynthesized by $S$. violaceoruber ES crude metabolite revealed synergistic effect to gentamicin especially against muti-drug resistant $P$. aeruginosa. The action of AgNPs may overcome the mechanism of bacterial resistance to antibiotics. AgNPs synergistic effect to antibiotics was reported by Fayaz et al. (2010). They proposed that it was due to formation of AgNP-antibiotic complex by chelating that lead to more serious damage to bacterial cells.

\section{Conclusion}

This research provides $S$. violaceoruber ES as an excellent microbial resource for low cost green synthesis route of AgNPs within minutes using sun light. The produced AgNPs has superior properties regarding to yield, shape, size and bactericidal efficiency. Further study will be designed to physically characterize AgNPs and chemically identify the pigment of $S$. violaceoruber ES to achieve full understanding of this promising process as an introduction to large scale application.

\section{References}

Alani, F., Moo-Young, M. and Anderson, W (2012) Biosynthesis of silver nanoparticles by a new strain of Streptomyces sp. compared with Aspergillus fumigatus. World Journal of Microbiology and Biotechnology, 28, 1081-1086.

Altschul, S.F., Gish, W., Miller, W., Myers, E.W. and Lipman, D.J. (1990) Basic local alignment search tool. Journal of Molecular Biology, 215, 403-410.

Altschul, S.F., Madden, T.L., Schaffer, A.A., Zhang, J., Zhang, Z., Miller, W. and Lipman, D.J. (1997) Gapped BLAST and PSI-BLAST: A new generation of protein database search programs. Nucleic Acids Research, 25 (17), 3389-3402.

Balakumaran, M.D., Ramachandran, R., Balashanmugam, P., Mukeshkumar, D.J. and Kalaichelvan, P.T. (2016) Mycosynthesis of silver and gold nanoparticles: 
Optimization, characterization and antimicrobial activity against human pathogens. Microbiological Research, 182, 8-20.

Bhat, R., Deshpande, R., Ganachari, S.V., Huh, D.S. and Venkataraman, A. (2011) Photoirradiated biosynthesis of silver nanoparticles using edible mushroom Pleurotus florida and their antibacterial activity studies. Bioinorganic Chemistry and Applications, ID: 650979, doi:10.1155/2011/650979.

Cinelli, M., Coles, S.R., Nadagouda, M.N., Błaszczyński, J., Słowiński, R., Varma, R.S. and Kirwan, K.A. (2015) A green chemistry-based classification model for the synthesis of silver nanoparticles. Green Chemistry, 17, 2825-2839.

Clinical and Laboratory Standards document M2-A9 (2006) Performance standards for antimicrobial disk susceptibility tests: Approved standardNinth Edition, Clinical and Laboratory Standards Institute, Wayne, Pennsylvania, USA.

Duan, H., Wang, D. and Li, Y. (2015) Green chemistry for nanoparticle synthesis. Chemical Society Reviews, 44, 5778-5792.

El-Naggar, N. and Abdelwahed, A.M. (2014) Application of statistical experimental design for optimization of silver nanoparticles biosynthesis by a nanofactory Streptomyces viridochromogenes. Journal of Microbiology, 52 (1), 53-63.

El-Naggar, N.E., Abdelwahed, N.A.M. and Darwesh, O.M.M. (2014) Fabrication of biogenic antimicrobial silver nanoparticles by Streptomyces aegyptia NEAE 102 as eco-friendly nanofactory. Journal of Microbiology Biotechnology, 24 (4), 453-464.

Fayaz, A.M., Balaji, K., Girilal, M., Yadav, R., Kalaichelvan, P.T. and Venketesan, R. (2010) Biogenic synthesis of silver nanoparticles and their synergistic effect with antibiotics: A study against gram-positive and gram-negative bacteria. Nanomedicine: Nanotechnology, Biology and Medicine, 6, 103-109.

Kamel, Z., Saleh, M. and El namory, N. (2016) Biosynthesis, characterization and antimicrobial activity of silver nanoparticles from actinomycetes. Research J. Pharmaceutical Bio. Chem. Sciences, 7, $119-127$
Korn-Wendisch, F. and Kutzner, H.J. (1981) The family Streptomycetaceae. In: "The Prokaryote: A Hand Book on the Biology of Bacteria: Ecophysiology, Isolation, Identification, Application", Vol. I, Balows, A., Truper, H.G., Dworkin, M., Harder, W., Schleifer, K.H. (Ed.). pp. 921-995, New York: Springer-Verlag.

Krishnaraj, C., Jagan, E.G., Rajasekar, S., Selvakumar, P., Kalaichelvan, P.T. and Mohan, N. (2010) Synthesis of silver nanoparticles using Acalypha indica leaf extracts and its antibacterial activity against water borne pathogens. Colloids and Surfaces B: Biointerfaces, 76, 50-56.

Kumar, P.S., Balachandran, C., Duraipandiyan, V., Ramasam, D., Ignacimuthu, S. and Al-Dhabi, N.A. (2015) Extracellular biosynthesis of silver nanoparticles using Streptomyces sp. 09 PBT 005 and its antibacterial and cytotoxic properties. Applied Nanoscience, 5, 169-180.

Kumar, V., Bharti, A., Gusain, O.P. and Bisht, G.S. (2010) An improved method for isolation of genomic DNA from filamentous actinomycetes. Journal of Engineering and Technology Management, 2, 10-13.

Labeda, D.P., Goodfellow, M., Brown, R., Ward, A.C., Lanoot, B., Vanncanneyt, M., Swings, J., Kim, S.B., Liu, Z., Chun, J., Tamura, T., Oguchi, A., Kikuchi, T., Kikuchi, H., Nishii, T., Tsuji, K., Yamaguchi, Y., Tase, A., Takahashi, M., Sakane, T., Suzuki, K.I. and Hatano, K. (2012) Phylogenetic study of the species within the family Streptomycetaceae. Antonie van Leeuwenhoek, 101 (1), 73-104.

Loqman, S., Bouizgarne, B., Barka, E.A., Clément, C., von Jan, M., Spröer, C., Klenk, H.P. and Ouhdouch, Y. (2009) Streptomyces thinghirensis sp. nov., isolated from rhizosphere soil of Vitis vinifera. International Journal of Systematic and Evolutionary Microbiology, 59, 3063-3067.

Manikprabhu, D. and Lingappa, K. (2013a) Antibacterial activity of silver nanoparticles against methicillinresistant Staphylococcus aureus synthesized using model Streptomyces sp. pigment by photo-irradiation method. Journal of Pharmacy Research, 6, 255-260.

Manikprabhu, D. and Lingappa, K. (2013b) Microwave assisted rapid and green synthesis of silver nanoparticles using a pigment produced by Streptomyces coelicolor klmp33. Bioinorganic Chemistry and Applications, ID 341798: 5 pages. 
Manivasagan, P., Kang, K., Kim, D.G. and Kim, S. (2015) Production of polysaccharide-based bioflocculant for the synthesisof silver nanoparticles by Streptomyces sp. International Journal of Biology Macromolecules, 77, 159-167.

Mokhtari, N., Daneshpajouh, S., Seyedbagheri, S., Atashdehghan, R., Abdi, K., Sarkar, S., Minaian, S., Shahverdi, H.R. and Shahverdi, A.R. (2009) Biological synthesis of very small silver nanoparticles by culture supernatant of Klebsiella pneumonia. The effects of visible-light irradiation and the liquid mixing process. Materials Research Bulletin, 44, 1415-1421.

Mulvaney, P. (1996) Surface plasmon spectroscopy of nanosized metal particles. Langmuir, 12, 788-800.

Nonomura, H. (1974) Key for classification and identification of 458 species of the streptomycetes included in ISP. Journal of Fermentation Technology, 52, 78-92.

Radzig, M.A., Nadtochenko, V.A., Koksharova, O.A., Kiwi, J., Lipasova, V. and Khmel, I.A. (2013) Antibacterial effects of silver nanoparticles on gram-negative bacteria: Influence on the growth and biofilms formation, mechanisms of actions. Colloids and Surfaces B: Biointerfaces, 102, 300-306.

Rintala, H., Nevalainen, A., Ronka, E. and Suutari, M. (2001) PCR primers targeting the 16S rRNA gene for the specific detection of streptomycetes. Molecular and Cellular Probes, 15, 337-347.

Sadhasivam, S., Shanmugam, P. and Yun, K. (2010) Biosynthesis of silver nanoparticles by Streptomyces hygroscopicus and antimicrobial activity against medically important pathogenic microorganisms. Colloids and Surfaces B: Biointerfaces, 81, 358-362.

Saifuddin, N., Wong, C. and Yasumira, A. (2009) Rapid biosynthesis of silver nanoparticles using culture supernatant of bacteria with microwave irradiation. European Journal of Chemistry, 6(1), 61-70.

Sanjenbam, P., Gopal, J.V. and Kannabiran, K. (2014) Anticandidal activity of silver nanoparticles synthesized using Streptomyces sp. VITPK1. Journal de Mycologie Médicale, 24, 211-219.

Schon, R. and Groth, I. (2006) Practical thin layer chromatography techniques for diaminopimelic acid and whole cell sugar analyses in the classification of environmental actinomycetes. Journal of Basic Microbiology, 46, 243-249.

Selvakumar, P., Viveka, S., Prakash, S., Jasminebeaula, S. and Uloganathan, R. (2012) Antimicrobial activity of extracellularly synthesized silver nanoparticles from marine derived Streptomyces rochei. International Journal of Pharma and Bio Sciences, 3 (3), 188-197.

Shanmugaiah, V., Harikrishnan, H., Al-Harbi, A.S., Shine, K., Khaled, J.M., Balasubramanian, N. and Shyam, K.R. (2015) Facile synthesis of silver nanoparticles using Streptomyces sP.VSMGT1014 and their antimicrobial efficiency. Digest Journal of Nanomaterials and Biostructures, 10 (1), 179-187.

Shetty, P.R., Kumar, B.S., Kumar, Y.S. and Shankar, G.G. (2012) Characterization of silver nanoparticles synthesized by using marine isolate Streptomyces albidoflavus. Journal of Microbiology and Biotechnology, 22 (5), 614-621.

Sivalingam, P., Antony, J.J., Siva, D., Achiraman, S. and Anbarasu, K. (2012) Mangrove Streptomyces sp. BDUKAS10 as nanofactory for fabrication of bactericidal silver nanoparticles. Colloids and Surfaces B: Biointerfaces, 98, 12- 17.

Subashini, J., Khanna, V.G. and Kannabiran, K. (2014) Anti-ESBL activity of silver nanoparticles biosynthesized using soil Streptomyces species. Bioprocess and Biosystems Engineering, 37, 999 1006.

Tamura, K. and Nei, M. (1993) Estimation of the number of nucleotide substitutions in the control region of mitochondrial DNA in humans and chimpanzees. Molecular Biology and Evolution, 10, 512-526.

Tsibakhashvili, N.Y., Kirkesali, E.I., Pataraya, D.T., Gurielidze, M.A., Kalabegishvili, T.L., Gvarjaladze, D.N., Tsertsvadze, G.I., Frontasyeva, M.V., Zinicovscaia, I.I., Wakstein, M.S., Khakhanov, S.N., Shvindina, N.V. and Shklover, V.Y.(2011) Microbial synthesis of silver nanoparticles by Streptomyces glaucus and Spirulina platensis. Nanomaterials: Applications and Properties, 2, 306-310.

Wang, Z., Chen, J., Yang, P. and Yang, W. (2007) Biomimetic synthesis of gold nanoparticles and their aggregates using a polypeptide sequence. Applied Organometallic Chemistry, 21, 645-651. 
Wei, X., Luo, M., Li, W., Yang, L., Liang, X., Xu, L., Kong, P. and Liu, H. (2012) Synthesis of silver nanoparticles by solar irradiation of cell-free Bacillus amyloliquefaciens extracts and $\mathrm{AgNO}_{3}$. Bioresource Technology, 103 (1), 273-278.

Williams, S.T., Goodfellow, M. and Alderson, G. (1989) Genus Streptomyces Waksman and Henrici 1943, 339AL. In: vol. 4: "Bergey's Manual of
Systematic Bacteriology" (1 $1^{\text {st }}$ ed.), Williams, S.T., Sharpe, M.E., Holt, J.G. (Ed.), Baltimore, Lippincott Williams \& Wilkins Company.

Zonooz, N.F. and Salouti, M. (2011) Extracellular biosynthesis of silver nanoparticles using cell filtrate of Streptomyces sp. ERI-3. Scientia Iranica Transactions F: Nanotechnology, 18, 1631-1635.

(Received 29/4/2017;

accepted 11/7/2017)

\title{
سترييتوميسيس فيولاسبيروبير إى إس: منتج لمواد أيضية للتخليق السريع و الآمن لجزيئات

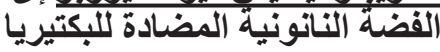

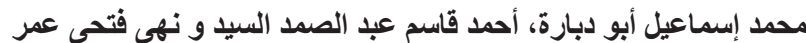

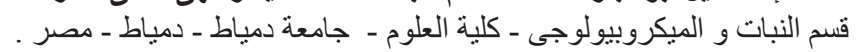

\begin{abstract}
عزلة جديدة من جنس السترييتو ميسيس تم توصيفهاو تعريفها مظهريا و فسيولوجيا على أنها سترييتو ميسيس

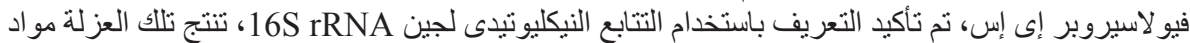

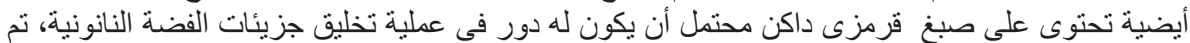

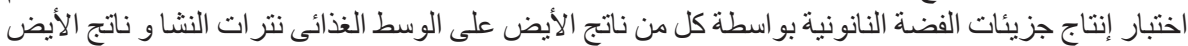

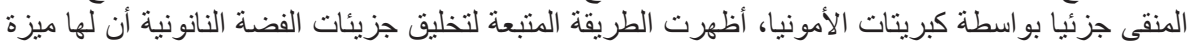

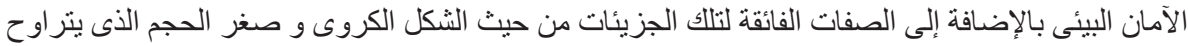

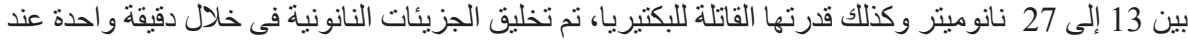

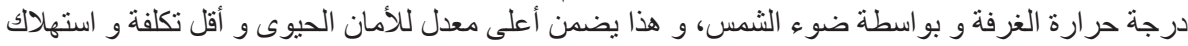

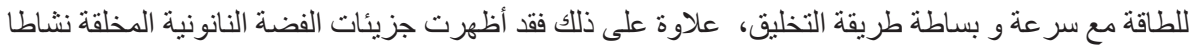

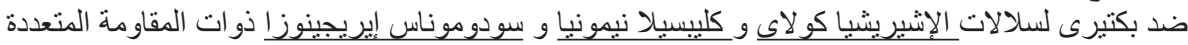

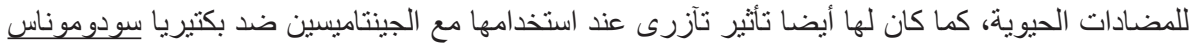

إيريجينوز ال المطات.
\end{abstract}

